Xueliang Xiao*, Hao Chen and Kun Qian

\title{
Thermomechanical study of polyethylene porous membrane by coating silicon dioxide nanoparticles
}

DOI 10.1515/secm-2015-0229

Received June 1, 2015; accepted November 27, 2015; previously published online April 6, 2016

\begin{abstract}
Polyethylene (PE) membrane has been extensively used in microtransport areas due to its high porosity, chemical stability, and easy processability. However, pure $\mathrm{PE}$ membrane shows poor thermomechanical properties. In this paper, silicon dioxide $\left(\mathrm{SiO}_{2}\right)$ was used to composite $\mathrm{PE}$ membrane in nanogel format. The morphology of the combination and surface layer was demonstrated by scanning electron microscopy (SEM) and atomic force microscopy (AFM). The $\mathrm{SiO}_{2}$ gel on membrane was analyzed by Fourier transform infrared (FTIR), energy-dispersive X-ray spectroscopy (EDX), and X-ray diffraction (XRD). The effect of the $\mathrm{SiO}_{2}$ gel on the thermomechanical properties of $\mathrm{PE}$ membrane was investigated in terms of thermal shrinkage, thermogravimetric analysis (TGA), and dynamic mechanical analysis (DMA). The results showed that the $\mathrm{SiO}_{2}$ gel effectively reduced the thermal shrinkage of $\mathrm{PE}$ membrane by $47.25 \%$ without increased crystallinity, and the coating layer slowed down the decomposed speed of PE membrane at melting point. Comparison tests showed that $\mathrm{SiO}_{2}$ gel enlarged the storage modulus and Young's modulus of PE membrane. Tensile test revealed that the maximum load on pure PE and PE composite membranes at the yield point were both decreased with the increased temperature.
\end{abstract}

Keywords: polyethylene; silicon dioxide; sol-gel coating; thermomechanical property.

\footnotetext{
*Corresponding author: Xueliang Xiao, Key Laboratory of Eco-Textiles, Ministry of Education, Jiangnan University, Wuxi, P.R. China, e-mail:xiao_xueliang@163.com Hao Chen: Faculty of Engineering, University of Nottingham (Ningbo Campus), Ningbo, P.R. China

Kun Qian: Key Laboratory of Eco-Textiles, Ministry of Education, Jiangnan University, Wuxi, P.R. China
}

\section{Introduction}

Polyethylene (PE) membrane, a kind of porous thin film with countless microfibrils after dry or wet double stretching in manufacture, has been widely used in industrial applications related to ion and fluid transfer areas [1-5]. Pure PE membrane shows high chemical stability, superhydrophobicity, and relatively stable porous structure [6-8]. However, the low temperatures of glass transition and melting of PE imply that the ion/fluid transfer can enhance the mobility of macromolecules and then disorder the alignment of molecular chains beyond a critical temperature value after the heat accumulation at the interface. This is shown as the thermal shrinkage of PE membrane [9], which is regarded as the great safety concern of PE membrane in use, especially when it works as a PE separator in battery $[10,11]$.

The combination with a kind of high melting point material can enhance the thermal safety of PE products $[10,12,13]$. The sol-gel coating process describes an effective way in combining the low melting temperature polymer with high melting point inorganics [14]. The process relates to a transition of a chemical solution in colloidal into an integrated network in a solid porous structure. The precursors used mostly in sol preparation are normally inorganic salts or metal organic compounds, such as metal alkoxide. The precursor is subject to a series of hydrolysis and polymerization reactions to become a colloidal suspension, namely, a sol. The liquid sol components can penetrate into the porous structural PE membrane and adhere to the surface of microfibrils. The sol then evolves towards an inorganic network containing a liquid gel phase due to the crosslinking of inorganic or organic compounds. The drying of the gel can remove the liquid phase, causing the formation of a porous structural material in and upon the PE membrane. In recent years, the sol-gel coating process has been used increasingly to introduce some functional matter on various forms of materials, such as steel [15], glass [16], and polymers [17].

In this article, we coated PE porous membrane with silicon dioxide $\left(\mathrm{SiO}_{2}\right)$ gel using a dipping $\rightarrow$ coating $\rightarrow$ drying 
approach. The surface morphology of the coated membrane was demonstrated by scanning electron microscopy (SEM) and atomic force microscopy (AFM). Fourier transform infrared (FTIR) and energy-dispersive X-ray spectroscopy (EDX) were used to analyze the composite structure of $\mathrm{PE} / \mathrm{SiO}_{2}$ gel. The effect of $\mathrm{SiO}_{2}$ gel on PE thermomechanical properties was studied using flame-close reaction, thermogravimetric analysis (TGA), dynamic mechanical analysis (DMA), and temperature rise in stretching.

\section{Materials and methods}

\subsection{Materials}

A roll of PE membrane (with thickness of $8 \mu \mathrm{m}$ ) was used in this study. The membrane samples were all first washed in ethanol (EtOH) followed by two rinses in distilled water and then were dried at $40^{\circ} \mathrm{C}$ in an oven.

\subsection{Preparation of $\mathrm{SiO}_{2}$ sol}

The $\mathrm{SiO}_{2}$ sol was prepared by mixing precursors tetraethyl orthosilicate (TEOS; CAS:78-10-4) and EtOH (98\%) at room temperature with high-speed stirring. $\mathrm{HCl}$ was then added into the mixture as a catalyst followed by deionized water and dimethylformamide (DMF), which were mixed into the system as buffers. The five liquid materials were mixed at a molar ratio of 1:8:0.04:3:1.6 (TEOS/EtOH/HCl/ $\mathrm{H}_{2} \mathrm{O} / \mathrm{DMF}$ ), and the reaction formula is as follows:

$$
\mathrm{Si}\left(\mathrm{OC}_{2} \mathrm{H}_{3}\right)+4 \mathrm{H}_{2} \mathrm{O}=\mathrm{Si}(\mathrm{OH})_{4}+4 \mathrm{C}_{2} \mathrm{H}_{3} \mathrm{OH}
$$

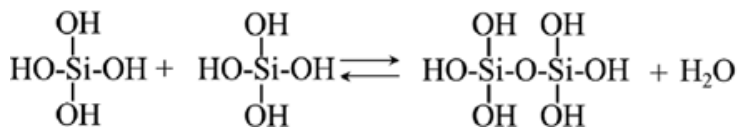

Formula (1) is the hydrolysis reaction using the $\mathrm{HCl}$ catalyst, and Formula (2) is the condensation of the hydrolysis products. The two-step reactions were going at the same time. The preparation of $\mathrm{SiO}_{2}$ was carried out for approximately $6 \mathrm{~h}$ at $30^{\circ} \mathrm{C}$ with high-speed stirring. A kind of stable, thick, transparent liquid sol was then formed after the reaction.

\subsection{Sol-gel coating on membrane}

The samples of PE membrane were immersed in the asprepared sol for $30 \mathrm{~min}$. The wet PE membranes were then rolled on a very smooth surface plate by a glass bar. These steps were repeated twice. The extra liquid on the sample surface was absorbed by paper tissue. The membrane samples were then dried in an oven at $40^{\circ} \mathrm{C}$ for $1 \mathrm{~h}$. The working principle is shown in Figure 1.

\subsection{Surface characterization}

\subsubsection{SEM and AFM characterization}

The surface morphology of $\mathrm{PE}$ and $\mathrm{PE} / \mathrm{SiO}_{2}$ gel membranes were observed using SEM (JEOL Model JSM-6490). EDX (JEOL Model Oxford INCA Energy 250) was used for chemical element confirmation. AFM (CSPM4000; Benyuan Company) was employed to measure the dimensions of dried gel particles, where the tapping mode was used. All samples under SEM observation were scanned at room temperature in nitrogen, whereas samples under AFM were scanned at ambient atmosphere.

\subsubsection{FTIR and X-ray diffraction (XRD) analysis}

The chemical functional groups of $\mathrm{PE}$ and $\mathrm{PE} / \mathrm{SiO}_{2}$ gel membranes were examined by FTIR spectroscopy (Perkin-Elmer Spectrum 100 FTIR Spectrometer, USA) in the range of 4000-650 $\mathrm{cm}^{-1}$ using attenuated total reflectance (ATR)-Ge method. The absorption spectra were recorded with 64 scans with a resolution of $16 \mathrm{~cm}^{-1}$. The crystallinity of $\mathrm{PE}$ and $\mathrm{PE} / \mathrm{SiO}_{2}$ gel membranes was measured by XRD (Rigaku SmartLab 9KW XRD System) with $2 \theta$ values from $15^{\circ}$ to $30^{\circ}$ and recorded at a scan speed of $3^{\circ} \mathrm{min}^{-1}$ at $40 \mathrm{kV}$ and $40 \mathrm{~mA}$, which was equipped with $\mathrm{Cu} \mathrm{K} \alpha$ radiation with a wavelength of $1.54 \AA$.

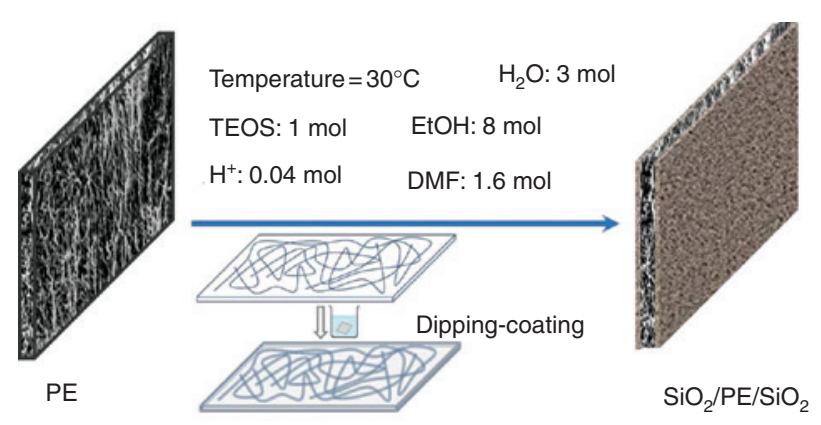

Figure 1: Schematic illustration of $\mathrm{SiO}_{2}$ sol preparation and PE membrane by sol-gel coating. 


\subsection{Thermomechanical investigation}

\subsubsection{Thermal shrinkage}

For comparison of thermal stability, $\mathrm{PE}$ and $\mathrm{PE} / \mathrm{SiO}_{2}$ gel membranes were implemented as follows: (a) the burning behavior was achieved close to the alcohol burner and recorded by the camera and (b) the membrane samples were heated in vacuum oven from room temperature to $120^{\circ} \mathrm{C}$ with a heating rise rate of $5^{\circ} \mathrm{C} \mathrm{min}^{-1}$ and maintained at $120^{\circ} \mathrm{C}$ for $15 \mathrm{~min}$. The thermal stability of the composite membranes was expressed by variation of the membrane size. The larger change of membrane size means poorer thermal stability under high temperature.

\subsubsection{Thermomechanical analysis}

The thermomechanical performance of $\mathrm{PE}$ and $\mathrm{PE} / \mathrm{SiO}_{2}$ gel membranes was studied by TGA (Mettler Toledo TGA/ DSC-1 Thermal-Analyser, Switzerland), DMA (PerkinElmer Diamond, DMA, USA), and Instron-5566 universal test machine with a heat chamber (Instron Calibration Lab, 5566Q7582). The investigations of samples by TGA, DMA, and Instron-5566 were all using nitrogen as purge gas, and temperature parameters were set from $20^{\circ} \mathrm{C}$ to $700^{\circ} \mathrm{C}$ with a heating rate of $10^{\circ} \mathrm{C} \mathrm{min}^{-1}$, from $20^{\circ} \mathrm{C}$ to $150^{\circ} \mathrm{C}$ with a heating rate of $2^{\circ} \mathrm{C} \mathrm{min}{ }^{-1}$, and from $30^{\circ} \mathrm{C}$ to $120^{\circ} \mathrm{C}$ $\left(30^{\circ} \mathrm{C}, 60^{\circ} \mathrm{C}, 90^{\circ} \mathrm{C}\right.$, and $\left.120^{\circ} \mathrm{C}\right)$ with an elongation rate of $10 \mathrm{~mm} \mathrm{~min}^{-1}$, respectively.

\section{Results and discussion}

\subsection{Analysis of thermal stability}

As is known, the thermoplastic polymer has a nature of shrinking and melting when close to fire flame. This is owing to the enhanced mobility of long macromolecular chains and increased entropy for the unstable orientation of molecules under heat accumulation [18]. This shrinkage is obviously illustrated as shown in Figure $2 \mathrm{~A}$ with black curly bead close to flame. Comparably, solid integrated $\mathrm{SiO}_{2}$ gel blocks the curly shrinking of membrane, which fires directly after heat accumulation to the PE decomposed temperature shortly. Quantitatively, two $2 \times 2 \mathrm{~cm}$ square frames were marked on the surface of two kinds of membranes, and then the membranes were heated up to $120^{\circ} \mathrm{C}$ under vacuum for $30 \mathrm{~min}$. The two membranes experienced different size declines as the temperature increases, as shown in Figure 2B. Figure 2C shows that the area of marked frame on the PE membrane decreases from 4 to $1.77 \mathrm{~cm}^{2}(44.25 \%)$, and the area of $3.66 \mathrm{~cm}^{2}(91.5 \%)$ for shrinked $\mathrm{PE} / \mathrm{SiO}_{2}$ gel membrane under $120^{\circ} \mathrm{C}$, indicating the significant improvement of thermal stability of PE membrane when coated with $\mathrm{SiO}_{2}$ gel. The larger error bar of PE shrinkage variation discloses the uneven porous structure of PE membrane, which causes the anisotropic shrinkage under heating, whereas the filled solid $\mathrm{SiO}_{2}$ gel prevents the anisotropic shrinkage of PE membrane significantly.

\subsection{SEM, EDX, and AFM characterization}

Figure $3 \mathrm{~A}$ and $\mathrm{B}$ shows the surface morphology of PE and $\mathrm{PE} / \mathrm{SiO}_{2}$ gel composite membranes, where $\mathrm{PE}$ shows a porous structure due to the liquid-solid phase separation during membrane manufacture, and PE composite membrane displays a smooth surface of $\mathrm{SiO}_{2}$ gel layer. The $\mathrm{SiO}_{2}$ gel layer was analyzed by EDX with a point spectrum for confirming the Si-element existence (Figure 3D). AFM images (Figure 3C and D) show that the $\mathrm{SiO}_{2}$ gel layer of PE membrane consists of gel nanoparticles with diameters from 5 to $50 \mathrm{~nm}$ using cross-section analysis for an arbitrary blue line. This diameter range of nanoparticles can definitely penetrate into the internal pores among microfibrils as shown in Figure 3A. However, it is noted that the densely stacked nanoparticles may not contribute to the modification of PE membrane when applied to battery separators as the significant decrease of membrane porosity. The effect of densely coated $\mathrm{SiO}_{2}$ nanoparticles on $\mathrm{PE}$ membrane porosity was consistent with Jeong and Lee's work [19].

\subsection{FTIR, XRD, and TGA analysis}

In the XRD characterization of $\mathrm{PE}$ and $\mathrm{PE} / \mathrm{SiO}_{2}$ gel membranes (Figure 4A), characteristic peaks can be identified at $21.6^{\circ}$ and $24.2^{\circ}$ of $2 \theta$. The sample crystallinity obtained from XRD was approximately $40 \%$ for PE and $15 \%$ for PE/ $\mathrm{SiO}_{2}$ gel membranes according to Eq. (3) [20]:

$$
\mathrm{Xc}=\frac{A_{\mathrm{T}}-A_{\mathrm{A}}}{A_{\mathrm{T}}}
$$

where $A_{\mathrm{T}}$ denotes the total area of the diffractogram and $A_{\mathrm{A}}$ denotes the area corresponding to the amorphous region. Thus, it is inferred that no crystalline phase exists inside the $\mathrm{SiO}_{2}$ gel after coating based on the same abscissas of peaks of the two scanned curves.

The effect of coated $\mathrm{SiO}_{2}$ gel on PE membrane was analyzed by FTIR, as presented in Figure 4B. The high 
A
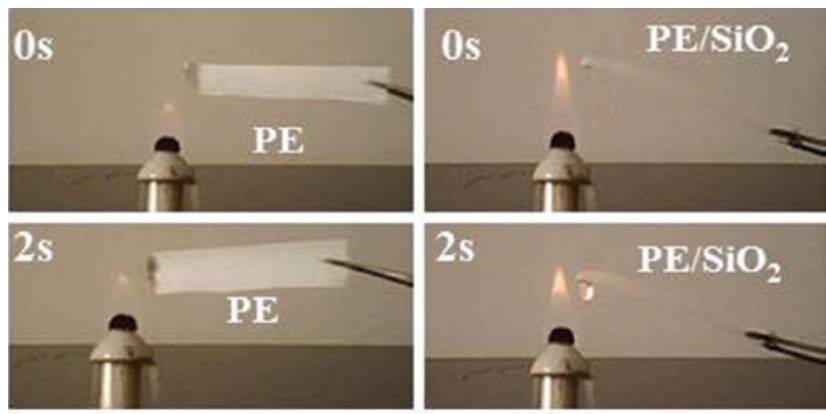

B
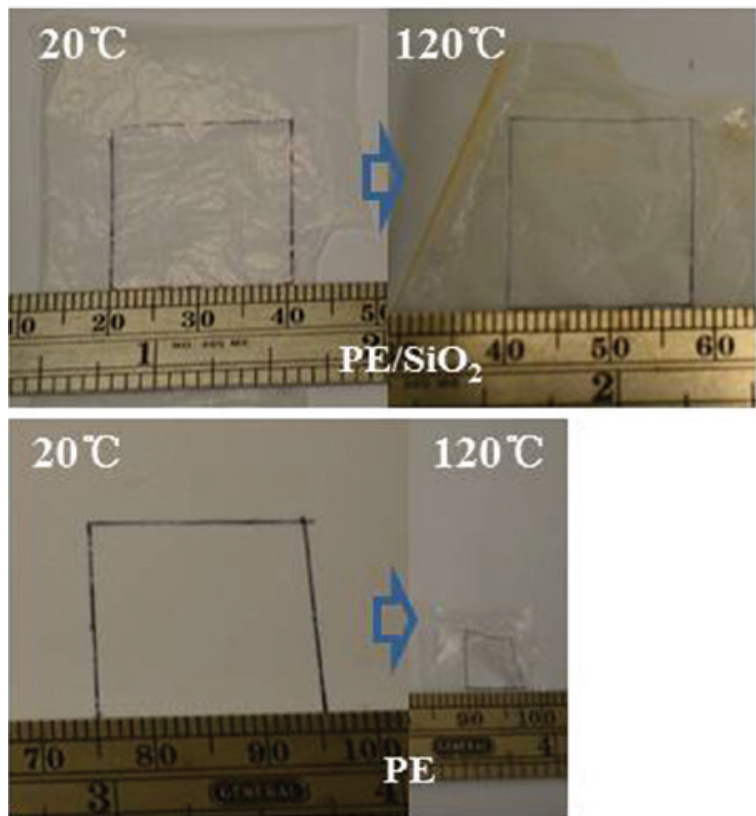

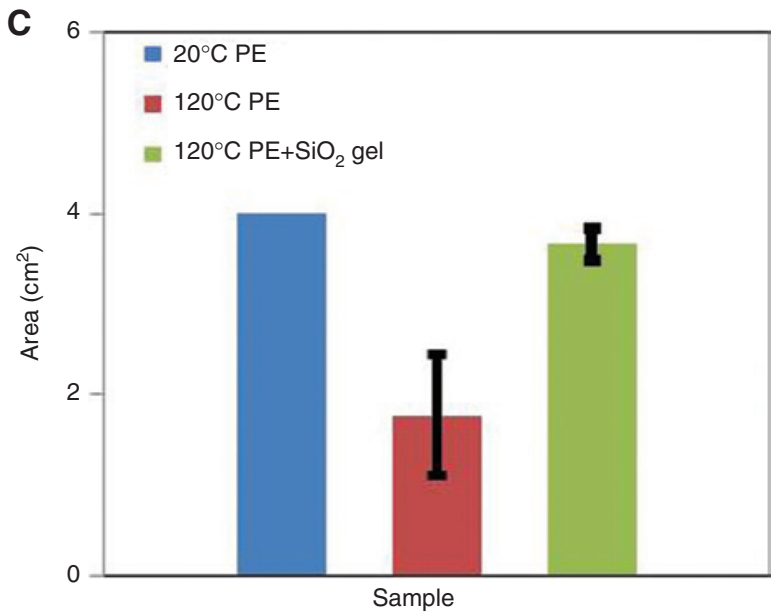

Figure 2: Thermal stability of PE membranes and $\mathrm{PE} / \mathrm{SiO}_{2}$ gel composites: (A) comparison of close-to-flame reactions; (B) and (C) area variation of both membranes under $20^{\circ} \mathrm{C}$ and $120^{\circ} \mathrm{C}$.

peaks from 720 to $2916 \mathrm{~cm}^{-1}$ demonstrated organic signals, such as a characteristic spectra of the asymmetric stretching vibration band of $\perp$-C-C- at the peak of $2916 \mathrm{~cm}^{-1}$ and symmetric stretching vibration band of $\|-\mathrm{C}-\mathrm{C}$ - at the peak of $2850 \mathrm{~cm}^{-1}$. The peaks at 1461 and $723 \mathrm{~cm}^{-1}$ indicated the existence of symmetrical curve vibration of $\perp$-C-C- at the $\mathrm{PE}$ crystal area and out-of-plane twist vibration of $\perp-\mathrm{C}-\mathrm{C}$ and $b$-axis of $\mathrm{CH}_{2}$ at the $\mathrm{PE}$ crystal areas. The characteristic peaks at 1651, 1066, and $973 \mathrm{~cm}^{-1}$ represent the $\mathrm{H}-\mathrm{OH}$ curve stretching vibration, the $\mathrm{Si}-\mathrm{OH}$ curve vibration, and the $\mathrm{Si}-\mathrm{O}-\mathrm{Si}$ asymmetric/symmetric stretching vibrations, respectively. These peaks prove the $\mathrm{SiO}_{2}$ gel on the $\mathrm{PE}$ membrane.

Figure $4 \mathrm{C}$ shows the measured weight percentage of $\mathrm{PE}$ and $\mathrm{PE} / \mathrm{SiO}_{2}$ gel membranes in the temperature range from $25^{\circ} \mathrm{C}$ to $700^{\circ} \mathrm{C}$. It is noted that $\mathrm{PE}$ membrane shows weight balance until its decomposed temperature at $475^{\circ} \mathrm{C}$, and the weight drops dramatically from this temperature. This is attributed to the porous structure and orientation disordering of PE macromolecular chains at decomposition and evaporation. However, the TGA curve of $\mathrm{PE} / \mathrm{SiO}_{2}$ gel membrane presents a slowly weight decrease with the increase of temperature and a dramatic weight drop at the same decomposed temperature of PE membrane, following with an almost constant line (residual weight) in the test temperature range. The slow reduction of weight indicates that the gel still contains sol-phase "liquid", which is locked inside the gel network and escapes at high temperature. The final residual $60 \%$ of weight is composed of $\mathrm{SiO}_{2}$ nanoparticles, which are not able to decompose in the test range of temperature.

\subsection{Analysis of thermostretching properties}

Figure 5 compares the surface morphologies of $\mathrm{PE}$ and $\mathrm{PE} /$ $\mathrm{SiO}_{2}$ gel membranes under stretching at $120^{\circ} \mathrm{C}$. There are a 

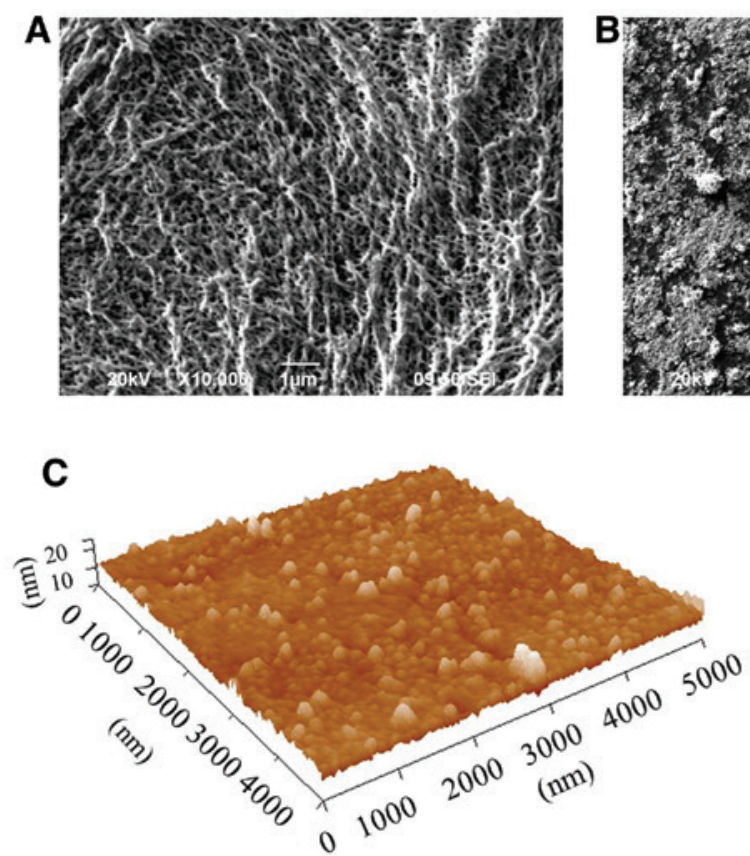
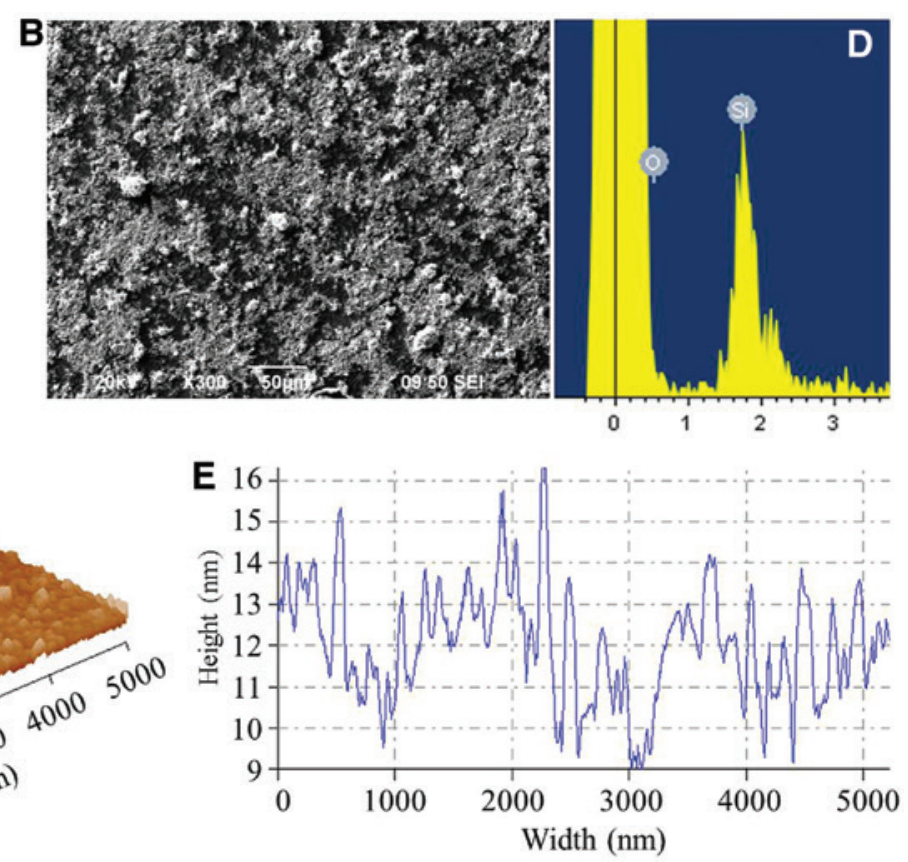

Figure 3: $\mathrm{SEM}$ images of (A) PE membrane and (B) $\mathrm{PE} / \mathrm{SiO}_{2}$ composite membrane and EDX observation of Si element on PE membrane and AFM images of $(\mathrm{C}) \mathrm{SiO}_{2}$ gel nanoparticles, (D) confirmation of $\mathrm{Si}$ element deposited on the PE membrane and (E) $\mathrm{SiO}_{2}$ gel particle dimension distribution.
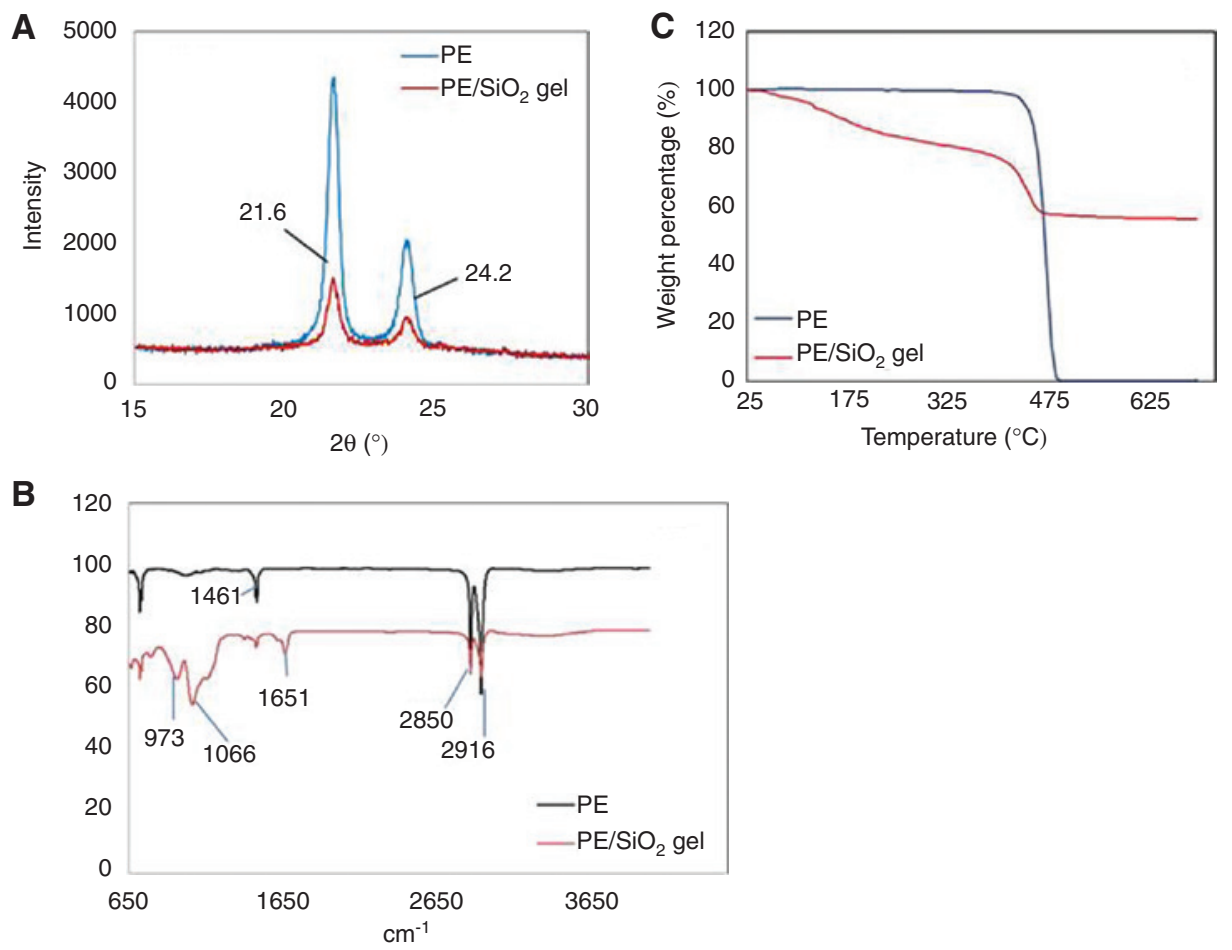

Figure 4: Testing results of $\mathrm{PE}$ membrane and $\mathrm{PE} / \mathrm{SiO}_{2}$ gel composites from (A) XRD, (B) FTIR, and (C) TGA.

number of white lines in parallel alignment on the surface of pure $\mathrm{PE}$ membrane, which is attributed to the reorientation of -C-C- molecular chains under large elongation at high temperature. These white lines are covered by $\mathrm{SiO}_{2}$ gel particles on the $\mathrm{PE} / \mathrm{SiO}_{2}$ gel membrane, which displays slight extrusion tendency of $\mathrm{SiO}_{2}$ gel particles as shown in the red arrows in Figure 5, indicating the resistance of $\mathrm{SiO}_{2}$ gel to the PE thermostretching behavior. 

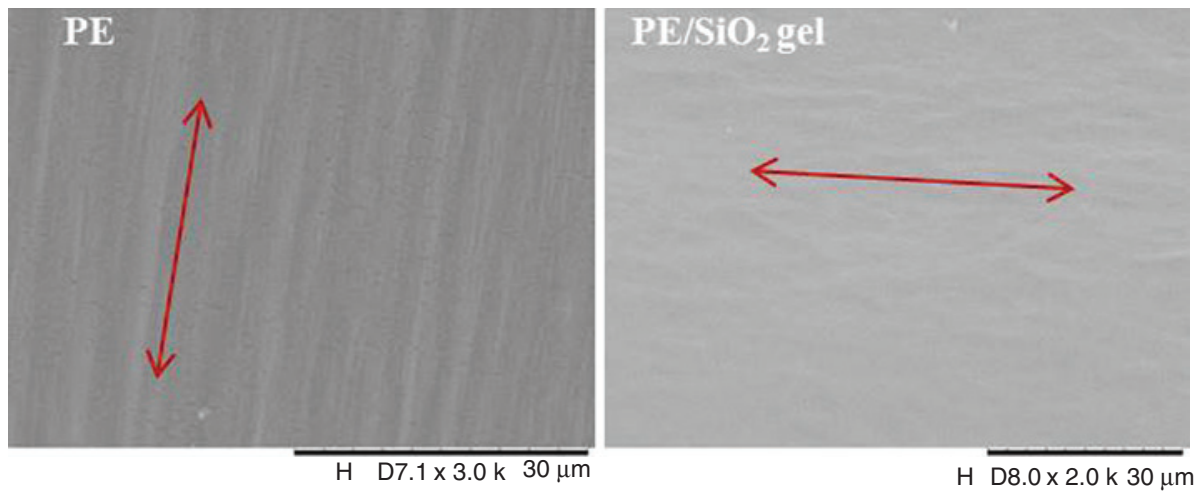

Figure 5: $\mathrm{SEM}$ images of $\mathrm{PE}$ membrane and $\mathrm{PE} / \mathrm{SiO}_{2}$ gel composites under stretching at $120^{\circ} \mathrm{C}$.

Figure 6 gives the results of DMA tests regarding the storage modulus $\left(E^{\prime}\right)$ and phase angle $(D)$, which are the function of temperature $(T)$ for the two membranes. Two plateaus appear as the glass- and rubbery-like states in Figure $6 \mathrm{~A}$, and the storage modulus reduces abruptly at $128^{\circ} \mathrm{C}$ for the $\mathrm{PE}$ and at $144^{\circ} \mathrm{C}$ for the $\mathrm{PE} / \mathrm{SiO}_{2}$ gel membranes, indicating that the coated $\mathrm{SiO}_{2}$ gel can enhance the glass transition temperature and the modulus of $\mathrm{PE}$ porous membrane to some extent. Oppositely, the phase angle reflects the ratio of the viscous portion to the elastic portion of a polymer. The angle of PE membrane is observed larger than that of the $\mathrm{PE} / \mathrm{SiO}_{2}$ gel membrane from Figure 6B. This implies a good thermal protection of $\mathrm{SiO}_{2}$ gel in preventing $\mathrm{PE}$ macromolecular chains from flowing above the glass transition temperature, owing to the stable thermal performance of $\mathrm{SiO}_{2}$ gel nanoparticles in the porous PE membrane.

During the Instron-5566 tensile tests, each sample dimension is a rectangle of $2.5 \times 5 \mathrm{~cm}$, and each one was performed under a series of constant temperatures. It is found that the maximum yield loads of both membranes decrease as the temperature increases from P30/PS30 $\left(30^{\circ} \mathrm{C}\right)$ to $\mathrm{P} 120 / \mathrm{PS} 120\left(120^{\circ} \mathrm{C}\right)$. The initial Young's moduli of the tested membrane (slope of curve) have the same tendency along the increasing temperature, as shown in the histograms in Figure 7. The membrane strain achieves a higher value at the maximum yield load under a higher temperature as shown in the curves in Figure 7, owing to the increased mobility of macromolecular chains and less crystallinity of the membrane. The coated $\mathrm{SiO}_{2}$ gel nanoparticles improve the Young's modulus of membrane significantly by two times higher than the pristine value, indicating the sufficient enlarged stiffness of the modified membrane. This is coincident with the enlarged storage modulus of $\mathrm{PE} / \mathrm{SiO}_{2}$ gel composite membrane from the DMA test.

\section{Conclusions}

This work investigates the effect of coated $\mathrm{SiO}_{2}$ gel on the thermomechanical properties of porous PE membrane. The SEM and EDX observations reveal the porous structure of PE membrane with dimension in nanoscale of pores and combination of $\mathrm{SiO}_{2}$ gel nanoparticles on the membrane surface. The dimensions of particles are also measured by AFM. FTIR and XRD measurements disclose the existence
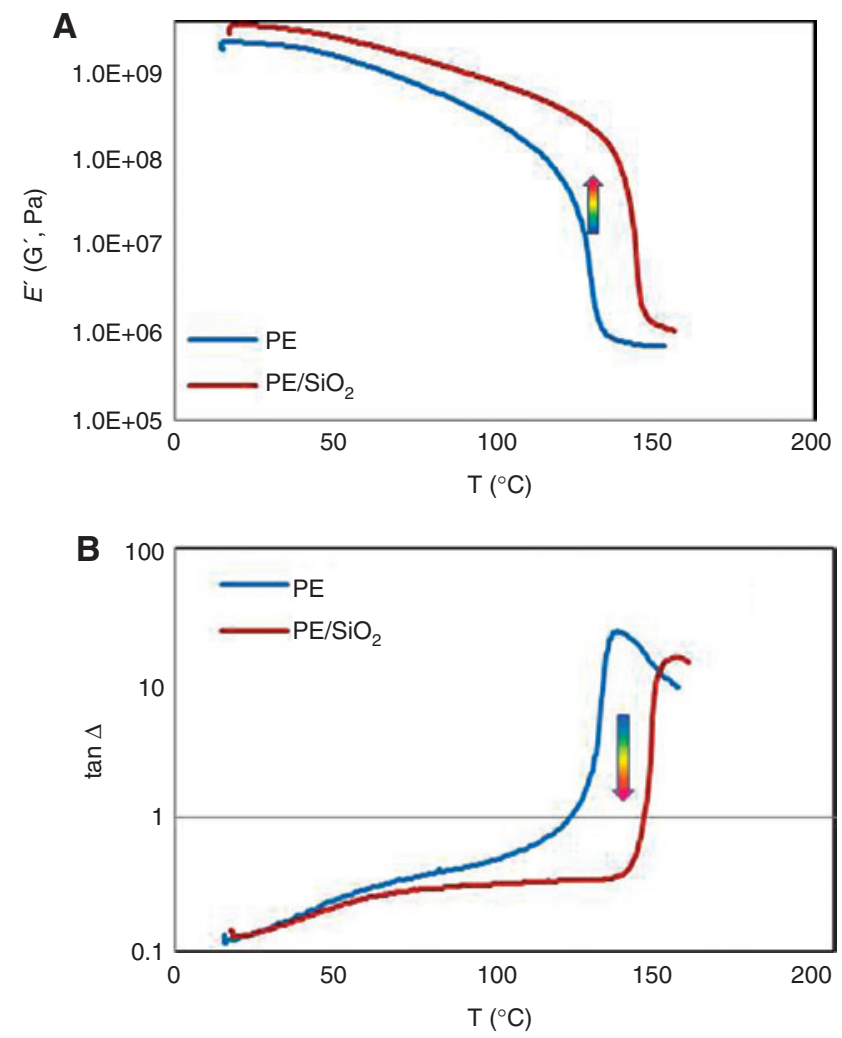

Figure 6: $\mathrm{DMA}$ of $\mathrm{PE}$ membrane and $\mathrm{PE} / \mathrm{SiO}_{2}$ gel composites along heating duration. 

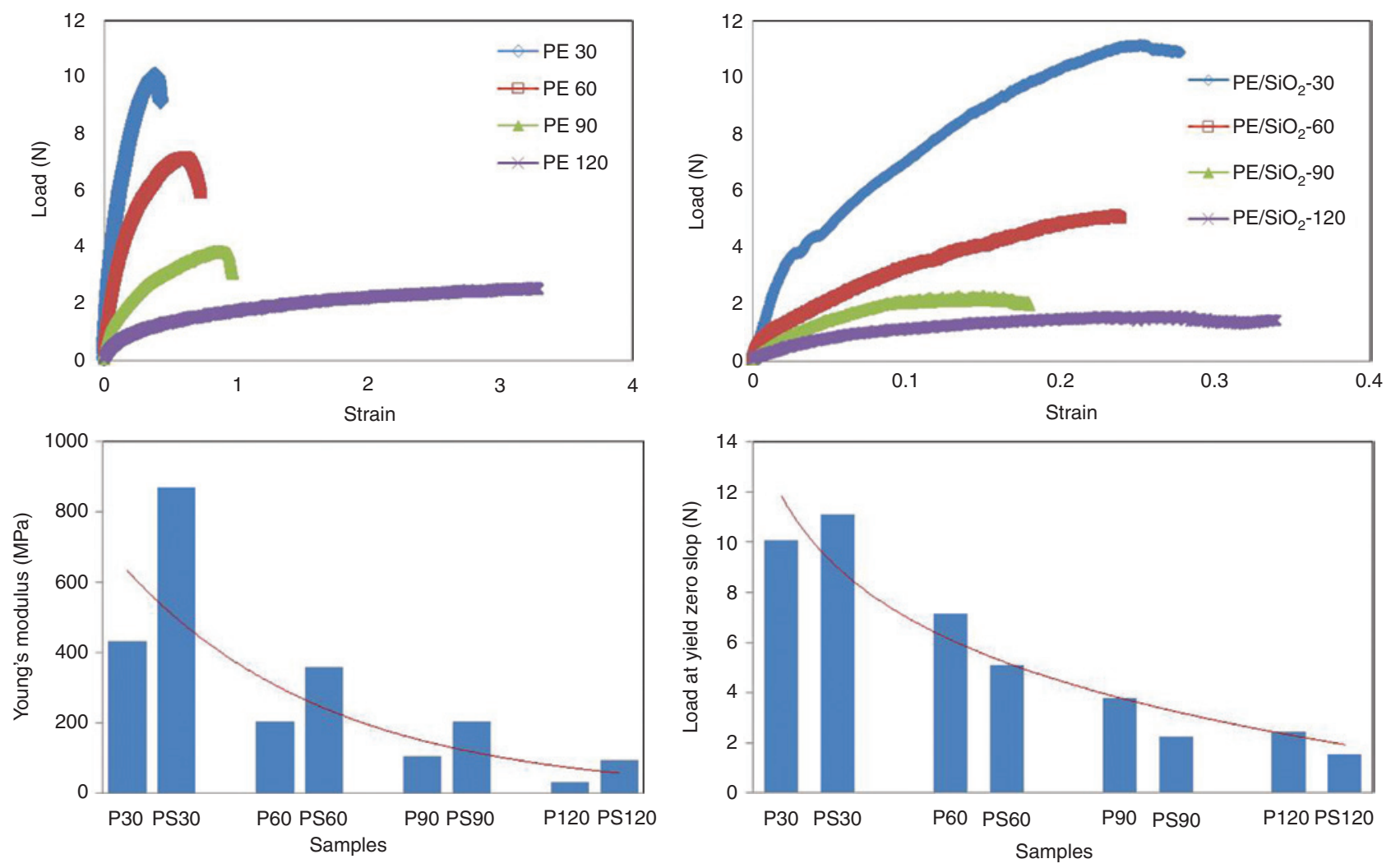

Figure 7: Thermotensile of membrane composites by Instron under $30^{\circ} \mathrm{C}, 60^{\circ} \mathrm{C}, 90^{\circ} \mathrm{C}$, and $120^{\circ} \mathrm{C}$.

of $\mathrm{Si}-\mathrm{O}$ and $\mathrm{C}-\mathrm{C}$ bonds in the $\mathrm{PE} / \mathrm{SiO}_{2}$ gel composite and decreased crystallinity by coated $\mathrm{SiO}_{2}$ gel. TGA test shows the slow decomposition of $\mathrm{SiO}_{2}$ gel for phase separation until the fully decomposed of PE membrane, indicating the net structure of gel in porous PE membrane. It is experimentally found that the coated $\mathrm{SiO}_{2}$ gel can prevent the PE membrane from thermal shrinkage significantly under the temperature of $120^{\circ} \mathrm{C}$, and the gel improves the membrane storage modulus, Young's modulus remarkably with the increased stiffness. The maximum load at yield and the modulus are both decreased with the increase of test temperature, and the gel has slight effect on the trend, indicating that the sol-gel coating has a slight effect on the thermomechanical properties of PE membrane.

Acknowledgments: The work was supported financially in part by the Project RGC No. 5158/13E and the National Natural Science Foundation of China Funding Grant No. 51373147 and Project code JC201104210132A.

\section{References}

[1] Bleha M, Kudela V, Rosova EY, Polotskaya GA, Kozlov AG, Elyashevich GK. Eur. Polym. J. 1999, 35, 613-620.
[2] Arora P, Zhang ZJ. Chem. Rev. 2004, 104, 4419-4462.

[3] Sohn JY, Gwon SJ, Choi JH, Shin J, Nho YC. Nucl. Instrum. Methods Phys. Res. B 2008, 266, 4994-5000.

[4] Huang X. J. Solid State Electrochem. 2011, 15, 649-662.

[5] Guan HY, Lian F, Ren Y, Wen Y, Pan XR, Sun JL. Int. J. Miner. Metallurg. Mater. 2013, 20, 598-603.

[6] Zhang C, Bai Y, Sun Y, Gu J, Xu Y. J. Membr. Sci. 2010, 365, 216-224.

[7] Schauer J, Brozova L. J. Membr. Sci. 2005, 250, 151-157.

[8] Gupta B, Anjum N. J. Appl. Polym. Sci. 2001, 82, 2629-2635.

[9] Zhang SS. J. Power Sources 2007, 164, 351-364.

[10] Choi JA, Kim SH, Kim DW. J. Power Sources 2010, 195, 6192-6196.

[11] Kang SM, Ryou MH, Choi JW, Lee H. Chem. Mater. 2012, 24, 3481-3485.

[12] Xiao X, Long A. Sci. Eng. Compos. Mater. 2014, 21, 99-109.

[13] Umberto P. Sci. Eng. Compos. Mater. 2014, 21, 197-204.

[14] Xiao X, Chen F, Wei Q, Wu N. J. Coat. Technol. Res. 2009, 6, 537-541.

[15] Checmanowski JG, Szczygieł B. J. Non-Cryst. Solids 2008, 354 , 1786-1795.

[16] Zhao X, Zhao Q, Yu J, Liu B. J. Non-Cryst. Solids 2008, 354, 1424-1430.

[17] Bessiere A, Badot JC, Certiat MC, Livage J, Lucas V, Baffier N. Electrochim. Acta 2001, 46, 2251-2256.

[18] Woo JJ, Nam SH, Seo SJ, Yun SH, Kim WB, Xu T, Moon SH. Electrochem. Commun. 2013, 35, 68-71.

[19] Jeong HS, Lee SY. J. Power Sources 2011, 196, 6716-6722.

[20] Poley LH, Siqueira APL, da Silva MG, Vargas H. Polimeros Cienc. Tecnol. 2004, 14, 8-12. 